\title{
FIRST-HANDS' CONTRIBUTION IN BUSINESS INQUIRY BASED ON QUALITATIVE INQUIRY OF ASSESSING ENVIRONMENTALISM INITIATIVES
}

\author{
Saeed, BEHJATI \\ Islamic Azad University - Roudehen Branch - Iran, behjati.ir@gmail.com
}

\begin{abstract}
This is a report paper, provides the key philosophies of underpinning qualitative methodology, which is utilized in business inquiry of assessing corporate environmentalism initiatives. It begins with an overview of research philosophy and ontology/epistemological platforms and the choice of inductive method that shapes the ways to conduct social inquiry. It follows by description of case study design, including the purists and pragmatists' debate on case study research and justification of the required data and collection methods. The end up is details analysing techniques of collected data and validity/reliability leverage.
\end{abstract}

KEY WORDS: Research Paradigms, Case Study Research, Qualitative Investigation, Rigor-Relevance Methods of Validation

\section{PHILOSOPHICAL ASSUMPTIONS}

The basic meaning of 'paradigm' is a specific way of viewing the reality and studding the knowledge and interpreting based upon the purpose of the inquiry (Mackenzie and Knipe, 2006). Research paradigms can be described as revealing guideline, which is framed by "set of beliefs and feelings about the real world and the way of breaking down this complexity that can be understood and studied." (Patton, 1990; Guba, 1990). Guba and Lincoln (1994) highlight the importance of paradigm as a structure of inquiry that shaped by ontology (nature of existence, reality or what is there that can be known), epistemology (concerned with nature, source and limitation of knowledge or the framework by which knowledge is acquired and validated), and methodological (the way inquirer should go to establish the knowledge of reality). Dash (2005) categories paradigms into two major clusters of positivism (in which the knowledge can be observe and measure) and the category of anti-positivism which is also known as interpretivist (in which the knowledge is produced by synthesis of meaning within interpretive approach). Creswell (2007, p.16) has pointed out four clusters of philosophical assumption in qualitative inquiry consist of post-positivism, social constructivism, advocacy or participatory and pragmatism. Guba and Lincoln (1994) framed structure of subjective inquiry based on post-positivism approach where the ontology assumed as critical realism, meaning that reality is exist while imperfectly "due to flawed human intellectual mechanisms and the fundamentally intractable nature of phenomena" (Guba and Lincoln, 1994, p.110).

And on the other hand, the epistemology emphasis more on the way gains the reality, accurately and scope of knowledge and the limits of human understanding. Basically, ontological assumption and personal views about the form and nature of reality successively, affect the epistemological consideration and the way to gain knowledge of that reality. Since the ontological assumption in post-positivist approach, embrace internal reality, therefore epistemological consideration more valuing participants' own interpretations of perceived reality. It maintains that knowledge creates from achieving deep understanding of the phenomenon and the context it is embedded in "however findings always subject to falsification" (Guba and Lincoln, 1994, p.110).

Further, in methodology, emphasis is more "based on 'critical multiplism' as a way of falsifying rather than verifying hypotheses. Post-positivist aims doing inquiry in more natural settings, collecting more situational information and reintroducing discovery as an element in inquiry. Research in the field of the social sciences particularly considers the soliciting emic viewpoints or the way people think to assist in determining the meanings and purposes that people ascribe to their actions" (Guba and Lincoln, 1994).

\section{RESEARCH VISIONING}

The purpose of this study was to explore in-depth the question about the executives' pattern of thinking or system of beliefs and nature of commitment about their corporate environmentalism, associated with existing institutional isomorphism. The aim was to fill the gap between implementation intention and intended behavior in complying with environmentalism.

Since the industrial revolution, carbon dioxide dramatically levels up; ironically, it has caused hazard to the well-being of this planet (Hoskins, 2013). Industries being the culprit behind the pollution have been claiming to take responsibility toward environment. Despite of long term implication of environmental programs and general consensus and enforcement on encouraging companies to focus on environmental practice, many organizations especially39 
small/medium firms are failing to make this compliance (Camacho, 2012; Jamali, Zanhour, \& Keshishian, 2009). While extensive literature has drawn model of decision-making and influencing factors on environmental behaviours, the essence of change or the development of commitment to environment have not adequately explained and many questions are left unanswered on how does corporate environmental responsiveness embedded in managers' pattern of thinking which it leads to actual intended behavior.

\section{METHODOLOGICAL DESIGN}

To be in consistent with scientific inquiry, the philosophical framework of this study grounded on realist view, where the reality exists associated with values, knowledge and experience of human beings. In other word the reality influence by human own thoughts, interpretations and meanings (Creswell, 2007). According to Guba and Lincoln (1994, p. 107) the facts and values cannot be separated because knowledge is positioned based on ones and the events. Particularly, in a study about executive pattern of thinking and the nature of their corporate environmentalism, the need was to be open to the beliefs, attitudes and values of the individuals. This issue was confirmed as all informants of this study, interfere their own unique statements and interpretations of the reality and existing knowledge or values that demonstrate the organization's strategy. It was perceived that, external reality manifests through fundamental aspects of human belief system and environmental situation. Therefore, due to complexity of human behavior and restrained comprehension about the essence of their mind-set, this issue can be comprehended only to a limited extent as describe by participants; and furthermore, it couldn't be possible to have a true picture of social realities without considering the context within which it occurred. Therefore, subjectivity of the problem feeds into the existing reality and in aims to provide detailed descriptions of why things are the way they are, the case study research methodology is found suited and research framed based on systematic procedures in consistence with Yin (2003) orientation and constructed through informant's view which is interpreted within their social context.

Such an inductive approach explores the waves of reality or meaning making logic with aimed improving the decisionmaking, organizational guiding principle or practice (Elliott \& Lukes, 2008; Kervin et al., 2006; Torrance in Somekh \& Lewin, 2005). Noted that in case study, the researcher role differs based on grounded methodological paradigm. For instance, in practice, researchers in post-positivist approaches maintain a distant observer role with the intention to explore an insider's perspective and contribute to social theory (Torrance in Somekh \& Lewin, 2005).

The method of inquiry in this research structured based on post-positive approach in consistence with guideline illustrated by Creswell (2007). Accordingly, the research was constructed in series of logically related steps, espouse the rigorous method of inductility collection of data, validation and analysis approach. Divergence in this structure the befitting source of data, alleged in individuals' and multiple perspectives rather organizational base and single reality. Reporting the inquiry also has been shaped based on post-positivism approach as it takes the form of scientific reports (e.g., problem, questions, data collection, result, and conclusion). Interpretative position of this study leans toward creating knowledge for better understanding of a phenomenon, which cannot be answered by positivist causal relationship of finite elements. It believes that the knowledge exists, on exterior to the researcher's meaning, derived by facts, and value in line with participants-oriented which is merely interpreted by researcher. Typically, the Interpretative stance of this research is exploring the managerial pattern of thinking as a value-laden process, which cannot be separated, from their real life involvement and values. Therefore, and according to Creswell (2007) the case study methods are apposite in the articulation of the particular phenomenon, which very little is known about and locked in the subjective human creation of meaning. Among other paradigm (worldviews) post-positivist approaches defined by Creswell (2007, p. 20) found appraise for this study as it considers the reductionism attributes, logical increments placed on principles of cause and effect and deterministic based on prior theories.

This method of discovery in current study involves constructing meaning that is grounded in the logic behind everyday activities. Particularly this perception regarded as models of social situations or social processes in representation of the corporate environmentalism. The basic understanding or an explanation of the problem at hand, developed from the codes and concepts derived from the language and meanings of "social actors". In other word, extracted concepts derived from the subjective reality, which is taken certain traits into informants' pattern of thinking.

\section{RESEARCH SAMPLE}

In conformity with qualitative gurus such as Yin (1977) and Creswell (2007) three purposefully chosen contrasting cases were deemed sufficient to illustrate elements resides within corporate environmentalism- nature relationship. Particularly, a small number of cases nuanced shades of meaning grounded in individuals' behavior. Corresponded with the Yin (2003) preferably in multiple case study rather than single cases, bounded numbers of cases were meant to prevent overwhelming with the detail of additional cases. Particularly this approach recommended when cases may not be representative of the drawn population or the specific elements of attitude, beliefs, experience, and outcome or also the situation is more desirable. This type of case study is also distinct from the many studies, as it fits in perspectives have taken by this research on top executives pattern of thinking which is considered as being important in corporate wider commitments on environmentalism initiatives.

Selected different enterprise in other hand was also due to certain similarities and potential contrasts, which aimed to extend insight into an issue under investigation. Since different organization focuses on different aspect of environmental responsiveness, therefore different selection of divers' organization was meant to gather insight as many attributes of responsiveness as possible. Considered similarities between the enterprises were in consisting of:

a) Selection based on the size and type of enterprise: All chosen cases are SMEs and within manufacturing cluster of industries.

b) Cases are demonstrating the environmentalism commitments: Cases were chosen because they are implementing environmental sustainability-based business models that reflect some aspects of the environmentalism perspective.

c) Selection was based on growth ambition and life cycle stage of the business: Cases are considered to be the pioneer "awarded as most sustainable company" in restructuring successful business model around commitments of40 
environmentalism.

d) Cases were accepted to participate in several round data collection and validation.

The offered contrast was not limited in operating in different industries. These manufacturers also exhibited different priorities within their environmentalism orientation as they nominated as pioneers because generally extended their commitments beyond the basic requirements of organizational construction of environmentalism.

\section{DATA COLLECTION}

The primary source of data were 10 in-depth, semi-structured interviews with top executives from range of CEO's and head officers related to research concerned issue within each organization. Interviews were all based on developed protocol to guide the rigors of inquiry. Each interviews proceeds approximately around one to two hours. They were recorded, sorted and transcribed in appropriate feature for the efficient analysing session. The secondary data were consisting of publicly available reports, public documents of sustainability recognized initiatives and journal articles. The main focused was understanding the nature in relation to the business operation. Observation source was included on-site interviews ranging from strategy and operations in consistent with the organization's ethos and values. Particularly, the main concern was comparison between actual actions and reality which is practices in link with participant's statements about beliefs and values and their perception in complying with corporate environmentalism.

\section{DATA ANALYSIS}

To be in consistence with Yin (1994), a typical case study database was assisted in maintaining a chain of evidence from initial source of transcribed interviews, documents abridged and field notes up to eventual case study conclusions. Collected data transcribed and analysed thematically, with particular emphasis on the expressed understandings of patterns of thinking and nature of the transformation to intended behavior. The Atlas.ti software package was used to excerpt and sort the codes and recorded memos from the actual words or terms discussed and used by the interviewees or summarized concepts developed through document review, and site visits. The process of thematic analysis involved first reducing the content based on contextual relevance with particular focuses on statements relating to the informant's visions, beliefs or nature of commitments, environmentalism concern as well as ambitions, difference or adherence to organizational culture, policy or social norms, achievements and confronted challenges and also inferences related to each case. As Strauss $\&$ Corbin (1998) recommended the process of summarizing the concepts (constructed codes) into themes was proceeding until no new codes were created and it was assumed that saturation had been achieved and there is no understatement in interviews expression and collected data.

In second stage, the thematic map schemed congruently in order to develop patterns (themes). The reduced data were regrouped systematically based on key similarities and differences in the participant expression (quotes) and understanding of nature and logic in construction of noted corporate environmentalism construction.

In the final stage, the relevant pattern extracted for all each theme inconsistent with research questions. The reciprocating process of analysing from emerged themes and the original data set was meant to achieve coherency, consistency, and distinctively in interpretation and making sense the nature of phenomenon rather than solely describing the issue.

In interpretation stage the specific meaning that derived from thematic analysis are clearly explicated. Unanticipated insights proposed in the report, offers the most nature-centered logic of corporate environmentalism. Extracted concepts supplemented with illustrative quotes from the transcribed interviews, in order to portray both the distinctive and comparable elements of the individuals-corporate environmentalism relationship.

While constraint pertains of using, a small number of cases did not allow for generalization (Yin, 1974) nevertheless, this issue was not the main intention of this study. The prime aim was to generate understanding the logic behind intended behaviours. Meaning making logics are developed to produce theoretical propositions that might further be tested by using of different method like deductive strategy.

\section{Essence of Validity/Relativity}

In aims to increase the reliability and validity of the research, several thorough while circumspect approaches were employed, such as (a) the transcript of the interviews and later the draft of the study report were re-send to validated by each informants; (b) Methodological and pragmatically procedures and developed perception were verified by the veracious experts. The table 1 illustrate the research trustworthiness scheme.

Table 1. Summary of Research Trustworthiness Scheme

\begin{tabular}{|c|c|c|}
\hline $\begin{array}{l}\text { Soundness } \\
\text { Indicators }\end{array}$ & Method & Detail \\
\hline \multirow{4}{*}{$\begin{array}{l}\text { Internal } \\
\text { Validity / } \\
\text { Credibility }\end{array}$} & $\begin{array}{c}\text { Prolonged } \\
\text { engagement in } \\
\text { filed }\end{array}$ & $\begin{array}{l}\text { Persistent observation and } \\
\text { field notes }\end{array}$ \\
\hline & $\begin{array}{l}\text { Use of peer } \\
\text { debriefing }\end{array}$ & $\begin{array}{c}\text { Elimination of granted biases } \\
\text { by blind checking of peers } \\
\text { and external reviewers }\end{array}$ \\
\hline & $\begin{array}{c}\text { Triangulation of } \\
\text { source and } \\
\text { investigators } \\
\end{array}$ & Cross case pattern matching \\
\hline & Member checking & $\begin{array}{c}\text { Participants involvement in } \\
\text { interpretation of their } \\
\text { transcribed response }\end{array}$ \\
\hline \multirow{4}{*}{$\begin{array}{c}\text { External } \\
\text { Validity/ } \\
\text { Transferability }\end{array}$} & \multirow{4}{*}{ Replication logic } & Multiple case studies \\
\hline & & Predetermined questioner \\
\hline & & $\begin{array}{c}\text { Define the scope and } \\
\text { boundaries in case study } \\
\text { protocol }\end{array}$ \\
\hline & & $\begin{array}{l}\text { Rigor procedure for coding } \\
\text { and analysing } \\
\end{array}$ \\
\hline \multirow[t]{2}{*}{$\begin{array}{l}\text { Objectivity } \\
\text { (Neutrality) } \\
\text { /Confirmability }\end{array}$} & $\begin{array}{l}\text { confirmability } \\
\text { audit and } \\
\text { triangulation of } \\
\text { multiple sources } \\
\text { of evidence }\end{array}$ & $\begin{array}{c}\text { Interview conducted with } \\
\text { decision makers of three } \\
\text { different SMEs manufacturer } \\
\text { and finding was confirmed } \\
\text { by respondent }\end{array}$ \\
\hline & $\begin{array}{l}\text { Practice } \\
\text { reflexivity }\end{array}$ & $\begin{array}{l}\text { Being critical self-reflection } \\
\text { about the phenomenon }\end{array}$ \\
\hline
\end{tabular}




\begin{tabular}{|c|c|c|}
\hline $\begin{array}{c}\text { Soundness } \\
\text { Indicators }\end{array}$ & Method & Detail \\
\hline & & $\begin{array}{c}\text { Ensure reliability of inquiry } \\
\text { by dense description of } \\
\text { research methodology } \\
\text { including literature control } \\
\text { and synthesis of finding }\end{array}$ \\
Deliability/ & Create audit trail & $\begin{array}{c}\text { Verification of both process } \\
\text { and finding by use multiple } \\
\text { external auditors }\end{array}$ \\
\cline { 2 - 3 } & Inquiry audit & \begin{tabular}{c} 
Deplity \\
\hline
\end{tabular}
\end{tabular}

\section{CONCLUSION AND DISCUSSION}

Ontologically speaking, in qualitative research, subjective reality exists as it is socially constructed by social actors. It holds to investigate, interpret and describe reality by empowering people to express the meaning and experience to construct the knowledge instead of considering them as objects of research (Tuli, 2011). By doing so, richness and deep understanding of reality by first-hand experience through social interaction in a specific context can be obtained (Bryman, 2004; Neuman, 2006). In this regards, reliable knowledge exists independently of individuals, and it comes from direct observation or manipulation of the natural phenomenon (Neuman, 2006; Tuli, 2011). Given these considerations, qualitative research strategy is deemed to be an appropriate method to answer any explorative research questions.

\section{ACKNOWLEDGEMENT}

This material is based on $\mathrm{PhD}$ research of author submitted to University Utara Malaysia and therefore he is grateful to Dr. Siti Norezam Othman who provided expertise of supervising and in that line improved the manuscript significantly.

\section{REFERENCES}

1. Bryman, A. (2004). Social research methods. Oxford university press.

2. Cresswell, J. W. (2007). Qualitative inquiry and research design: Choosing among five approaches. Lincoln: Sage.

3. Dash, K.K. (2005). Online research methods resource: Module - selection of the research

4. Elliott, J., \& Lukeš, D. (2008). Epistemology as ethics in research and policy: The use of case studies. Journal of Philosophy of Education, 42(s1), 87-119.
5. Guba, E. G., \& Lincoln, Y. S. (1994). Competing paradigms in qualitative research. In N. K. Denzin \& $Y$.

6. Kervin, L. Vialle, W. Herrington, J. \& Okely, T. (2006) Research for Educators. Sydney, Thomson - Social Sciences Press.

7. Mackenzie, N., \& Knipe, S. (2006). Research dilemmas: Paradigms, methods and methodology. Issues in educational research, 16(2), 193-205. Retrieved November 13, 2013, from University Utara Malaysia http://www.celt.mmu.ac.uk/researchmethods/Modules/Sele ction_of_methodology/index.php

8. Neuman, W. L. (2006). Social research methods: Qualitative and quantitative approaches. Boston, MA: Allyn \& Bacon.

9. Torrance, H. (2005) in Torrance, H. and Stark, S., 'Case study'. In Somekh, B. and Lewin, C. (eds). Research methods in the social sciences. London: Sage Publications.

10. Jamali, D., Zanhour, M., \& Keshishian, T. (2009). Peculiar strengths and relational attributes of SMEs in the context of CSR. Journal of Business Ethics, 87(3), 355-377.

11. Camacho, D. J.(2012). Improving the Environmental Effects of Business Practice Toward Corporate Social Responsibility. (Doctoral Dissertation, Walden University)

12. Patton, M. Q. (1990). Designing qualitative studies. Qualitative evaluation and research methods, 2, 145-198. John Wiley \& Sons, Ltd.

13. Yin, R. K. (2003). Case studies research: design and methods. Thousand Oaks, Sage.

14. Yin, R., (1994). Case study research: Design and methods (2nd ed.). Beverly Hills, CA: Sage Publishing.

15. Strauss, A., \& Corbin, J. (1998). Basics of Qualitative Research. Thousand Oaks.

16. Tuli, F. (2011). The Basis of Distinction Between Qualitative and Quantitative Research in Social Science: Reflection on Ontological, Epistemological and Methodological Perspectives. Ethiopian Journal of Education and Sciences, 6(1).

17. Guba, E. G. (Ed.). (1990). The paradigm dialog. Sage.

18. Hoskins, Ed (11 May 2013). Scientists call for action to tackle $\mathrm{CO} 2$ levels. BBC science \& environment. Retrieved from http://www.bbc.co.uk/news/science-environment22491491 